\title{
Ofuji disease: a rare dermatosis and its challenging therapeutic approach*
}

\author{
Fernanda Freitas de Brito ${ }^{1}$ \\ Maria Lopes Lamenha Lins Cavalcante ${ }^{1}$ \\ Gabriela Itimura $^{1}$
}

\author{
Antonio Carlos Ceribelli Martelli ${ }^{1}$ \\ Ana Cecília Versiani Duarte Pinto ${ }^{1}$ \\ Cleverson Teixeira Soares ${ }^{1}$
}

DOI: http:/ / dx.doi.org/10.1590/abd1806-4841.20164778

\begin{abstract}
Eosinophilic pustular folliculitis (EPF) or Ofuji disease is a rare dermatosis, prone to recurrence and chronicity. The peak incidence occurs in the third decade of life and its exact etiology remains unknown. Evidence suggests that the expression of adhesion molecules and the production of cytokines activate the follicular unit, but the stimulus that triggers these changes remains unclear. The three clinical variants reported in the literature include classic EPF, immunosuppression-associated EPF, and infancy-associated EPF. We report a case of eosinophilic pustular folliculitis with peculiar epidemiological characteristics, which represents a challenging therapeutic scenario.
\end{abstract}

Keywords: Skin Diseases; Pregnancy; HIV; Neutrophil infiltration

\section{INTRODUCTION}

Eosinophilic pustular folliculitis (EPF) or Ofuji disease is a rare dermatosis, prone to recurrence and chronicity. The peak incidence occurs in the third decade of life. ${ }^{1,2}$ In 1965, Ise and Ofuji described a case of a Japanese woman supposedly presenting a follicular variant of subcorneal pustular dermatosis. ${ }^{3}$ Her clinical picture consisted of follicular pustules on the face, back, and arms, as well as moderate leukocytosis with eosinophilia. ${ }^{4}$ In 1970, Ofuji et al. published three other cases proposing the term "eosinophilic pustular folliculitis". ${ }^{4}$ The first cases in children were described by Lucky in 1984..$^{5}$ Two years later, Soeprono and Schinella reported three cases of EPF in patients with HIV. ${ }^{2}$ The exact etiology of the disease remains unknown. Evidences suggest that the expression of adhesion molecules and the production of cytokines activate the follicular unit, but the stimulus that triggers these changes remains unclear. Factors that seem to induce EPF include hypersensitivity reactions, mites, fungal infections, abnormal eosinophils or $\mathrm{T}$ lymphocyte function, immune dysfunction caused by human immunodeficiency virus (HIV), and reconstitution of immune function in patients treated for HIV., ${ }^{1,2}$ The literature reports three clinical variants of the disease. Classic EPF is more frequent in Japan with a male predominance. Clinically, it is characterized by papular pustules $(1-2 \mathrm{~mm}$ in diameter) with a tendency to increase in size and merge, leading to the formation of erythematous plaques. Lesions are usually follicular and pruritic, chronic, and recurrent, with centrifugal extension and central clearing. Lesions typically take 7-10 days to heal and recur every 3-4 weeks. Classic EPF mainly affects the face and trunk. Less frequently, it can compromise extremities, palms and soles. ${ }^{1,4}$ Immunosuppression-associated EPF is the most common variant, often related to HIV infection. It mostly affects late-stage patients and/or with CD4 lymphocyte count below 250-300 cells/ $\mathrm{mm}^{3} .^{1,2,4}$ Infancy-associated EPF first appears between the second and tenth months of life, with papular-pustular lesions similar to the classic variant. However, lesions are almost exclusively seen on the scalp and without the characteristic annular pattern. ${ }^{1,4}$ We report a case of eosinophilic pustular folliculitis with peculiar epidemiological characteristics and its challenging therapeutic approach. 


\section{CASE REPORT}

A 29-year-old female patient referred to our institution with pruritic papular pustules on the face and upper limbs. She reported having used hair dye 15 days before the appearance of the lesions. Personal history revealed no comorbidities. Dermatological exam showed follicular papules and pustules, coalescing to form plaques on the face and extensor region of the upper limbs (Figures 1 and 2). Anatomic pathological examination revealed dermal inflammation, mostly composed of eosinophils and, to a lesser extent, neutrophils and mononuclear cells with follicular aggression - clinical picture suggestive of EPF (Figure 3). Patch test had positive reaction to lanolin, paraben-mix, and formaldehyde. Blood count revealed mild leukocytosis (11,500 cells $/ \mathrm{mm}^{3}$ - reference range (RR): 4500-11000 cells $\left./ \mathrm{mm}^{3}\right)$ with eosinophilia (6\% - RR: $\left.0 \%-5 \%\right)$. Serological tests for hepatitis B and C and HIV revealed negative results. Treatment started with cetirizine, topical corticosteroid and indomethacin. The patient improved considerably, but presented relapses when we reduced indomethacin dosage. After one year of treatment, the patient tested positive on beta-HCG (human chorionic gonadotropin). We suspended all medications and the patient showed total improvement of the lesions during pregnancy. In the first week after giving birth, the lesions on the face recurred, but resolved spontaneously after three days. The patient has been follow-up since then and we have reported no recurrent lesions for three years.
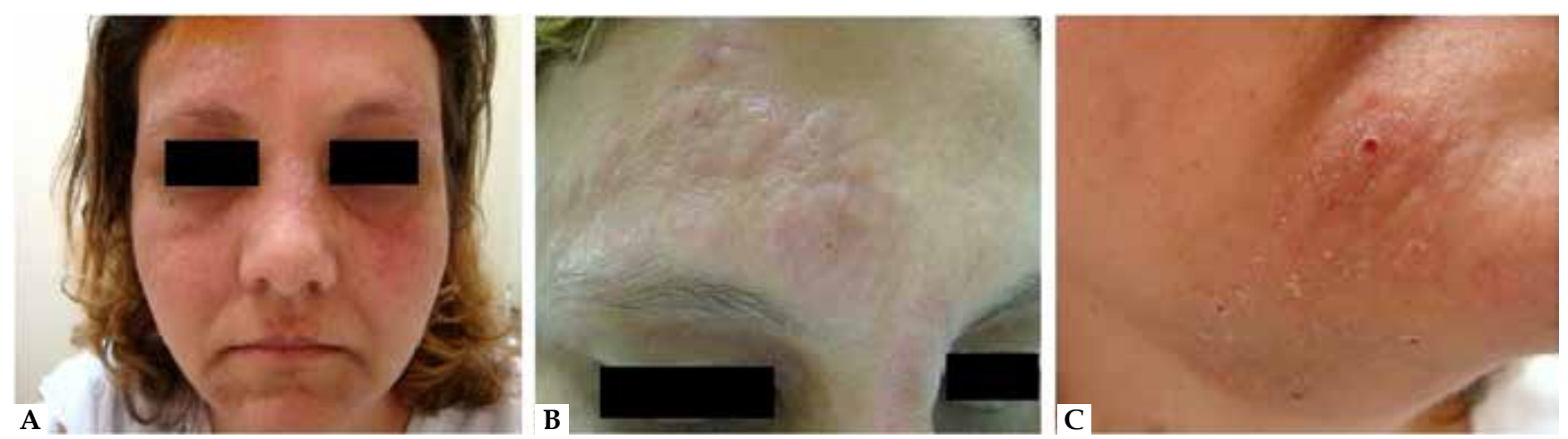

Figure 1: A. Follicular papules and pustules, coalescing to form plaques in frontal and right perioral areas. B. Details of confluent follicular papules forming erythematous plaques on the forehead. C. Detail of follicular papules on perioral area
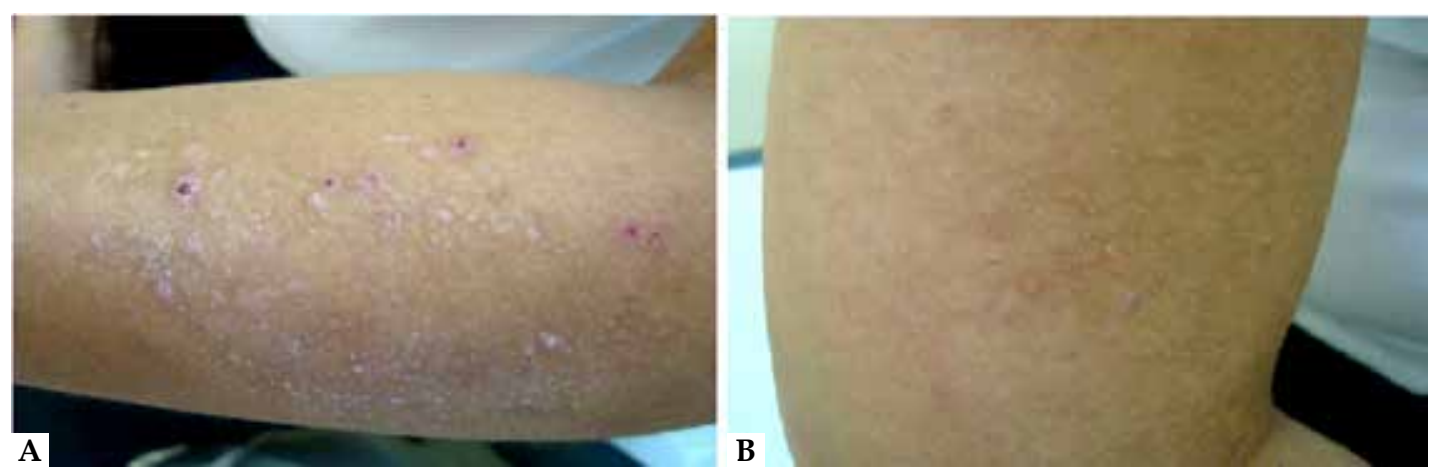

FiguRE 2:

$A$ and B. Follicular papules and pustules, some excoriated, on the extensor region of the upper limbs
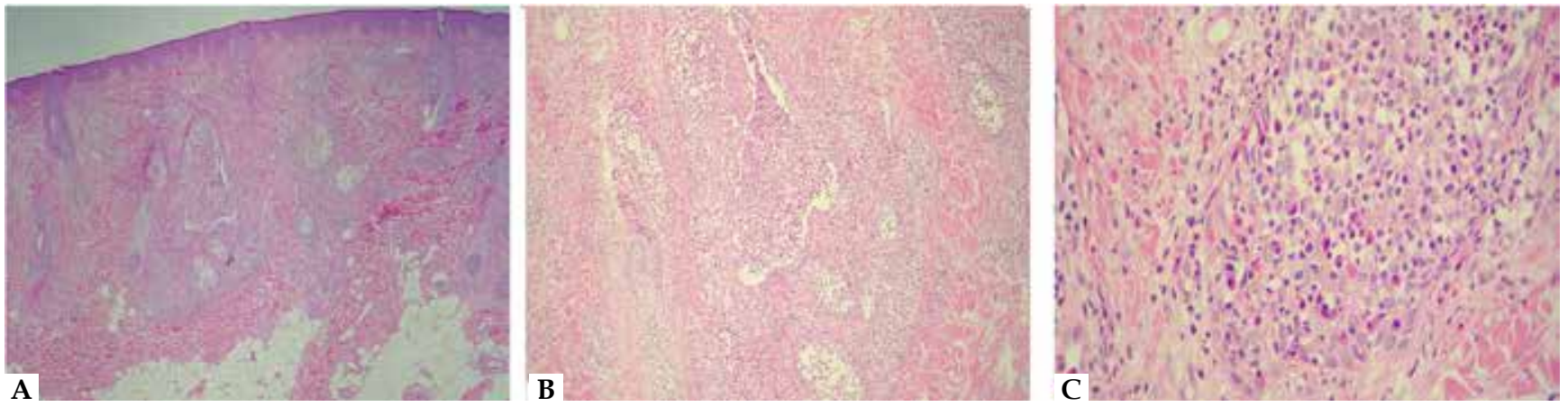

Figure 3: A. HE 50x: Folliculotropic inflammatory process in the superficial and deep dermis; B. HE 100x: Predominantly neutrophilic and eosinophilic inflammatory process with follicular aggression and basophilic material deposited in the follicular epithelium and interstitial; C. HE 400x: Intense follicular aggression mediated by eosinophils and neutrophils 


\section{DISCUSSION}

EPF is a pruritic cutaneous eruption that mainly occurs in Japanese people. ${ }^{1,6}$ Although HIV-associated EPF is the prevalent variant, our patient presented negative HIV serological examination. Our case was consistent with the classical variant of the disease (originally described by Ofuji), but the lesions affected a female western patient, which makes our case a rare occurrence. Laboratory tests showed mild leukocytosis with eosinophilia. Ofuji described the presence of peripheral eosinophilia in all of his cases. This change, however, is not always present. ${ }^{78}$ Another laboratory finding of the classic variant includes mild-to-moderate leukocytosis ${ }^{1,6}$ The etiology of the disease remains unknown, but in the present report - due to the chronological association of the skin lesions with hair dye use - we suggest that a hypersensitivity reaction may have triggered the lesions. Our diagnosis was made on clinical grounds based on anatomic pathological examination. The results showed inflammatory dermal infiltration mostly composed of eosinophils and neutrophils (to a lesser extent) and mononuclear cells with follicular aggression. ${ }^{1,4,6}$ Although various treatments have been attempted for EPF, the use of topical corticosteroids is usually the treatment of choice for all variants with satisfactory response. ${ }^{1,4}$ Indomethacin tends to be the oral treatment of choice for the classic variant, but relapse cases are frequently reported. ${ }^{1,6,9}$ Other treatment options include topical calcineurin inhibitors, systemic isotretinoin, phototherapy, minocycline, doxycycline, sulfamethoxazole/trimethoprim, erythromycin, dapsone, colchicine, and clofazimina. ${ }^{1,2,4}$ Our patient used topical steroids associated with antihistamine and indomethacin showing lesion stability. However, we reported recurrence after a decrease in indomethacin dose. According to the literature, immune diseases can improve or worsen during pregnancy. ${ }^{10}$ In the present case, we reported an overall clinical improvement during pregnancy. After delivery, lesions recurred and resolved spontaneously in three days. Due to recurrence and chronicity, EPF is difficult to treat. This report highlights the importance of considering EPF not only for Asian immunosuppressed patients and emphasizes the rarity of this disease that poses a therapeutic challenge to clinicians.]

\section{REFERENCES}

1. Razera F, Olm GS, Bonamigo RR. Dermatoses neutrofilicas - Parte II. An Bras Dermatol. 2011;86:195-211.

2. Ellis $\mathrm{E}, \mathrm{Scheinfeld} \mathrm{N.} \mathrm{Eosinophilic} \mathrm{pustular} \mathrm{folliculitis.} \mathrm{A} \mathrm{comprehensive} \mathrm{review} \mathrm{of}$ treatment options. Am J Clin Dermatol. 2004:5:189-97.

3. Ise S, Ofuji S. Subcorneal pustular dermatosis. A follicular variant? Arch Dermatol. 1965;92:169-71.

4. Nervi SJ, Schwartz RA, Dmochowski M. Eosinophilic pustular folliculitis: A 40 year retrospect. J Am Acad Dermatol. 2006:55:285-9.

5. Larralde M, Morales S, Santos Muñoz A, Lamas F, Schroh R, Corbella C Eosinophilic pustular in infancy: report of two new cases. Pediatr Dermatol. 1999; 16:118-20

6. Sufyan W, Tan KB, Wong ST, Lee YS. Eosinophilic pustular folliculitis. Arch Pathol Lab Med. 2007:131:1598-601.

7. Rosenthal D, LeBoit PE, Klumpp L, Berger TG. Human immunodeficiency virusassociated eosinophilic folliculitis. A unique dermatosis associated with advanced human immunodeficiency virus infection. Arch Dermatol. 1991;127:206-9.

8. Ishiguro N, Shishido E, Okamoto R, Igarashi Y, Yamada M, Kawashima M. Ofuji's disease: a report of 20 patients with clinical and histopathologic analysis. J Am Acad Dermatol. 2002;46:827-33.

9. Fukamachi S, Kabashima K, Sugita K, Kobayashi M, Tokura Y. Therapeutic effectiveness of various treatments for eosinophilic pustular folliculitis. Acta Derm Venereol. 2009:89:155-9.

10. Gutiérrez HIG, Iñiguez MJC, Mendoza SP, Ferreira MS. Enfermedad de Ofuji y embarazo. Comunicación de un caso. Ginecol Obstet Mex. 2006;74:158-63.

\author{
MAILING ADDRESS: \\ Fernanda Freitas de Brito \\ Rodovia Comandante João Ribeiro de Barros, km 225/226 \\ Distrito Industrial \\ 17039-800 - Bauru - SP \\ Brazil \\ E-mail:fernandabrito.dermatologia@gmail.com
}

How to cite this article: Brito FF, Martelli ACC, Cavalcante MLLL, Pinto ACVD, Itimura G, Soares CT. Ofuji disease: a rare dermatosis and its challenging therapeutic approach. An Bras Dermatol. 2016;91(5):646-8. 